\title{
The CFD Analysis of Solar Parabolic Trough System with Reflectors
}

\author{
Panchal Ramchandra $\mathbf{H}^{*}$ and Bhosale S.K. \\ Mechanical Department, Savitribai Phule Pune University, Trinity College of Engineering and Research, Pune, Maharashtra, India
}

Accepted 15 June 2016, Available online 20 June 2016, Special Issue-5 (June 2016)

\begin{abstract}
This paper was concerned with an experimental study of parabolic trough collector designed and manufactured. A parabolic trough solar collector uses Mirror and Aluminum foil in the shape of a parabolic cylinder to reflect and concentrate sun radiations towards an absorber tube located at the focus line of the parabolic cylinder. The receiver absorbs the incoming radiations and transforms them into thermal energy, the latter being transported and collected by water as a working medium circulating within the absorber tube. In this experimental setup, the reflected solar radiations were focused on absorber tube which was placed at focal length of the parabolic trough. To enhance the performance of parabolic trough, collector with different type of reflectors were used. It was observed for mirror has maximum temperature is $59.6^{\circ} \mathrm{C}$, which $14.22 \%$ more than Aluminum foil as reflector. Aluminum foil as reflector temperature is $53^{\circ} \mathrm{C}$ Efficiency by using Mirror as reflector compared to Aluminum foil as reflector is $18.98 \%$ more. The Designing and Fabrication of parabolic trough solar water heater for water heating was executed, the procedure employed includes design, construction and testing stages. The model which is made up of reflector surface, reflector support, absorber pipe and a stand with automatic tracking arrangement was fabricated using locally sourced material for rural applications point of view.
\end{abstract}

Keywords: Concentrated solar power, evacuated tube, parabolic trough collector, reflectors

\section{Introduction}

Solar energy is the primary source of energy for our planet. The average solar energy reaching the earth in the tropical zone is about $1 \mathrm{kwh} / \mathrm{m} 2$ and total radiation over a day is at best about $7 \mathrm{kwh} / \mathrm{m}^{2}$. The solar constant Isc is the rate at which energy is received from the sun on a unit area perpendicular to the rays of the sun, at the mean distance of the earth from the sun the value of Isc is $1353 \mathrm{w} / \mathrm{m} 2$. Increased utilization of solar energy in our country would result in all around benefits, both in terms of cleaner environment and monetary gain. The energy from the sun is used for various purposes mainly as power generation known as solar electricity generation system and industrial process heat applications. The few countries with long days and plenty of sunshine, especially in the Thar Desert region. On average, the country has 300 sunny days per year and receives an average hourly radiation of $200 \mathrm{MW} / \mathrm{km}^{2}$. The India Energy Portal estimates that around $12.5 \%$ of India's land mass, or 413,000 $\mathrm{km}^{2}$, could be used for harnessing solar energy. This zone, having abundant solar energy available, is suitable for harnessing solar energy for a number of applications. In areas with similar intensity of solar radiation, solar energy could be easily harnessed. Solar

*Corresponding author: Panchal Ramchandra H thermal energy is being used in India for heating water for both industrial and domestic purposes. A $140 \mathrm{MW}$ integrated solar power plant is to be set up in Jodhpur but the initial expense incurred is still very high. India receives solar energy equivalent to over 5000 trillion $\mathrm{kWh} /$ year, which is far more than the total energy consumption of the country. [10] In India the energy problem is very serious. In spite of discoveries of oil and gas off the west coast, the import of crude oil continues to increase and the price paid for it now dominates all other expenditure. As far as India is concerned there are 33 solar photovoltaic (PV) power plants with total 425.9 (MW) DC peak power and the total of 979.4 MW power productions throughout the country.

In our country use of solar trough is mainly for power generation, industrial process heat applications, and for this applications development of a commercial industry to produce and market these solar trough systems but now it's time to come use of solar trough for domestic applications and manufactured it by using locally available material.

In the present work, new parabolic trough collector system with Automatic tracking system which has been developed for hot water generation, Fabrication and design of a solar parabolic trough is done using locally available materials. The great advantage of solar trough is that it is clean, cheaper and can be supplied 
thermal energy without any environmental pollution. It there by directly substitutes renewable energy for fossil-fuels, non-commercial fuel namely- firewood and also helps to cut utility electricity bills. At rural level and remote areas this system can use for hot water generation, crop drying, Laundries, in dairy, Food preparation and service facilities hence low temperature trough will be a better solar thermal device for the rural area.

Sagade et al. conducted experiment on parabolic trough made of mild steel with its aperture area coated by aluminum foil with a reflectivity of 0.86 and Mirror with a reflectivity 0.98 . This line-focusing parabolic trough with copper tube receiver has been tested with glass cover. From Indian conditions, low-cost FRP parabolic trough system proves to be beneficial for industrial heating applications as well as domestic heating .

ValanArasu and Sornakumar explained the design and manufacturing of smooth $90^{\circ}$-rim angle, mild steel parabolic trough for water heating application. The total thickness of the parabolic trough is $2 \mathrm{~cm}$. The concave surface where the reflector is fixed is manufactured to a high degree of surface finish. They have found that the standard deviation of the distribution of the parabolic surface errors is 0.0066 radians from the collector performance test according to ASHRAE Standard 93 (1986), which indicates the high accuracy of the parabolic surface. Ruby et al. performed through the design, construction, operation, and analysis of a high temperature solar thermal system at a Frito-Lay snack food plant located in Modesto, California. In this installation, high temperature water is produced by a concentrating solar field, which in turn is used to produce approximately 300 pounds per square inch (20 bar) of process steam. Process steam in the plant is used for cooking, which includes heating edible oil for frying, and heating baking equipment. Steam is also converted into hot water for cleaning and sterilization processes.

\section{System description}

\section{A) Experimental set-up}

In Experimental setup, parabolic trough collector having an aperture area $1.4884 \mathrm{~m} 2$ and focal length $0.305 \mathrm{~m}$ is used for solar water heating. The schematic diagram and experimental setup of parabolic trough collector are shown in Fig.1

The system consists of following parts:

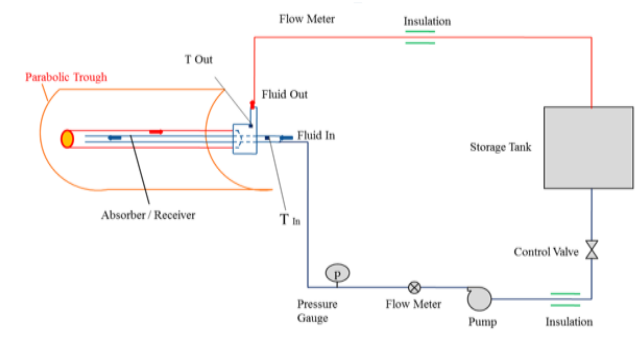

Fig.1 A line diagram of experimental set-up of PTSC's
The Storage tank used in the experimental set up is to be filled with the HTF which is used as a working fluid. HTF is circulated to the absorber tube with the help of a pump which is located inside the storage tank. The mass flow rate of HTF through the absorber tube is to be making constant $(\mathrm{kg} / \mathrm{s})$. During circulation it gains heat in the absorber tube and comes back in the storage tank. The HTF is then recirculating again and again through the absorber tube throughout the whole day. An evacuated glass cover tube is to be used over the copper tube to reduce the conduction, convection, and radiation losses. Two insulated pipes one from storage tank to the inlet of the absorber tube and other from the outlet of the absorber tube to the storage tank are used to carry the HTF from storage tank to the absorber tube. It is noted from literature survey that the peak temperature of the HTF is obtained at 01:00 $\mathrm{PM}$ and after that the temperature started decreasing due to the thermal losses from the absorber tube. The temperature at inlet and outlet to the absorber tube is to be measured by a thermocouple and which will be indicated by RTPTD 100. The temperature of the HTF in the storage tank is measured by a thermocouple which is completely dipped in HTF.

\section{B) Reflector}

Reflector is one of the vital parts of the parabolic trough collector as it decides the fraction of solar irradiance to be collected by the absorber tube. A parabolic reflector reflects a concentrates all the sun rays on the absorber tube. The reflector is a parabolic shaped Mirror and Aluminum Foil

\section{C) Absorber Tube}

The absorber tube is placed at the focal length of the parabolic trough collector. The outer diameter and inner diameter of absorber tube are $0.032 \mathrm{~m}$ and $0.030 \mathrm{~m}$ respectively along with a length of $1.22 \mathrm{~m}$. The solar radiations reflected by the parabolic trough collector are collected by the absorber tube. Water is used as working fluid in the absorber tube.

\section{D) Modified Evacuated Receiver Tube}

The solar receiver is the key component of a PTSC's, which plays a prominent role in the gross system efficiency. In order to improve the efficiency of the system heat gain of the system should increase. The useful heat gain of the PTC system is directly dependent on the heat loss from the receiver at its operating temperature. The receiver is designed to improve the energy conversion efficiency of concentrated sunlight to the thermal energy of HTF inside the absorber tube. Evacuated glass tube with the selective coating employed to control radiates and convective heat losses. Normally receivers of the PTSC's are single pass flow design, but in this system by inserting, the copper tube inside the evacuated tube creates a counter flow of HTF. 


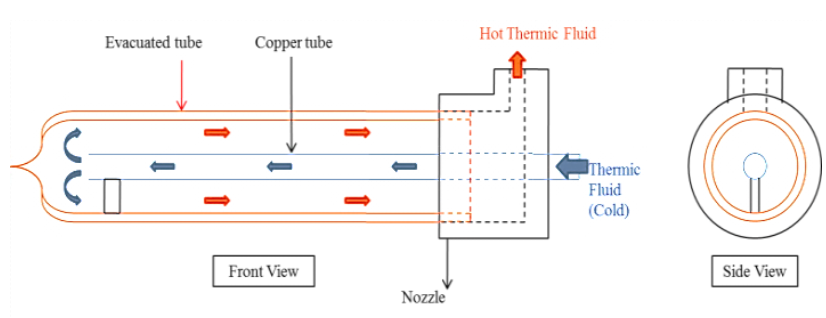

Fig. 2 a schematic diagram of modified evacuated receiver tube

\section{E) Selection Criteria for Heat Transfer Fluid}

Heat-transfer fluids carry heat through solar collectors to a heat exchanger and heat exchanger to the heat storage tanks in CSP systems. While selecting a heattransfer fluid, following criteria should consider:

- Temperature Range

- Viscosity

- Density

- Specific Heat

- Thermal Conductivity

- Compatibility

- Cost

- Environmental Impact

- Toxicity

- Flash point

- $\quad$ High Temperature \& Low temperature application

- $\quad$ Corrosiveness

- Stability

For example, in a cold climate, solar water heating systems require fluids with low freezing points. Fluids exposed to high temperatures, as in a desert climate, should have a high boiling point. Determination of the temperature range is extremely important. There is no point in discussing other fluid characteristics until the temperature range is satisfied. Once this criterion is fulfilled, other important fluid properties can be considered. (i.e., viscosity, density, specific heat and thermal conductivity) As per the application, must evaluate the compatibility, cost, environmental impact and toxicity of the heat transfer fluid.[10]

\section{Performance testing}

The performance of the system is determined by obtaining the values of collector instantaneous efficiency, overall thermal efficiency and the hourly thermal efficiency for different combinations of solar intensity of radiations, ambient temperature and the inlet heat HTF temperature. All parameters are measured as a function of time over one hour period under steady state conditions. The steady state equation describes the energy balance Equation for system:

$\mathrm{dq}_{\mathrm{u}}=\left[\mathrm{I}_{\mathrm{b}} \mathrm{r}_{\mathrm{b}}\left(\mathrm{w}-\mathrm{D}_{0}\right) \rho \gamma(\tau \alpha)_{\mathrm{b}}+\mathrm{I}_{\mathrm{b}} \mathrm{r}_{\mathrm{b}} \mathrm{D}_{0}(\tau \alpha)_{\mathrm{b}}-\right.$ $\left.\mathrm{U}_{\mathrm{L}} \pi \mathrm{D}_{0}\left(\mathrm{~T}_{\mathrm{p}}-\mathrm{T}_{\mathrm{a}}\right)\right] \mathrm{dx}$

Where,

$\mathrm{dq}_{\mathrm{u}}=$ Useful heat gain rate for a length $\mathrm{dx}$

$\rho=$ Specular reflectivity of the concentrator surface

$\gamma=$ Intercept Factor $=0.90$ $(\tau \alpha)=$ Average value of the transmissivity absorptivity product for beam radiation

$\mathrm{U}_{\mathrm{l}}=$ Overall loss coefficient

$\mathrm{T}_{\mathrm{p}}=$ Local temperature of the absorber tube

$\mathrm{T}_{\mathrm{a}}=$ Ambient temperature

The first Term of the Right hand side in above Eq. $\left(\mathrm{I}_{\mathrm{b}} \mathrm{r}_{\mathrm{b}}\left(\mathrm{w}-\mathrm{D}_{0}\right) \rho \gamma(\tau \alpha)_{\mathrm{b}}\right)$ represent the incident beam radiation absorbed in the absorber tube after reflection and the second term $\left(\mathrm{I}_{\mathrm{b}} \mathrm{r}_{\mathrm{b}} \mathrm{D}_{0}(\tau \alpha)_{\mathrm{b}}\right)$ represent the absorbed incident beam radiation which falls directly on the absorber tube. The second term is small in comparison with the first, but cannot be ignored when the concentration ratio is small. The third term $\left(\mathrm{U}_{1} \pi \mathrm{D}_{0}\left(\mathrm{~T}_{\mathrm{p}}-\mathrm{T}_{\mathrm{a}}\right)\right.$ ) represents the loss by convection and re-radiation.

A. Concentration Ratio (C)

Concentration ratio of the collector is given by:

$$
\mathrm{C}=\frac{\text { Effective aperture area }}{\text { Absorber tube area }}=\frac{\left(\mathrm{W}-\mathrm{D}_{\mathrm{po}}\right) \mathrm{L}}{\pi \mathrm{D}_{\mathrm{po}_{\mathrm{o}}} \mathrm{L}}
$$

\section{B. Absorbed Flux (S)}

Absorbed flux by the receiver tube is given by:

$$
S=I_{b} r_{b} \rho \gamma(\tau \alpha)_{b}+I_{b} r_{b}\left(\frac{D_{p o}}{\left(w-D_{p o}\right)}\right)(\tau \alpha)_{b}
$$

C. Collector Efficiency Factor (F')

Collector efficiency factor of the system is given by:

$\mathrm{F}^{\prime}=\frac{\frac{1}{\mathrm{U}_{\mathrm{L}}}}{\frac{1}{\mathrm{U}_{\mathrm{L}}}+\frac{\mathrm{D}_{\mathrm{po}}}{\mathrm{h}_{\mathrm{f}} \times \mathrm{D}_{\mathrm{pi}}}\left[\frac{\mathrm{D}_{\mathrm{po}}}{2 \times \mathrm{K}_{\mathrm{f}}} \times \ln \frac{\mathrm{D}_{\mathrm{po}}}{\left(\mathrm{D}_{\mathrm{pi}}\right)}\right]}$

D. Heat Removal Factor $\left(\mathrm{F}_{\mathrm{r}}\right)$

$\mathrm{F}_{\mathrm{r}}=\frac{(\dot{\mathrm{m}} \times \mathrm{Cp})}{\left(\pi \times \mathrm{D}_{\mathrm{po}} \times \mathrm{U}_{\mathrm{L}} \times \mathrm{L}\right)}$

E. Useful Heat Gain $\left(\mathrm{Q}_{\mathrm{u}}\right)$

$\mathrm{Q}_{\mathrm{u}}=\mathrm{F}_{\mathrm{r}}(\mathrm{W}-\mathrm{Do}) \mathrm{L}\left[\mathrm{S}-\frac{\mathrm{U}_{\mathrm{L}}}{\mathrm{C}}\left(\mathrm{T}_{\text {fin }}-\mathrm{T}_{\mathrm{a}}\right)\right]$

F. Instantaneous Efficiency Of Collector $\left(\mathrm{N}_{\mathrm{i}}\right)$

$$
\mathrm{n}_{\mathrm{i}}=\frac{\mathrm{Q}_{\mathrm{u}}}{\left[\left(\mathrm{I}_{\mathrm{b}} \mathrm{Xr}_{\mathrm{b}}\right)+\left(\mathrm{I}_{\mathrm{d}} \mathrm{Xr}_{\mathrm{d}}\right)\right] \mathrm{WL}}
$$

G. Instantaneous Efficiency Of Collector $\left(\mathrm{N}_{\mathrm{ib}}\right)$

Instantaneous efficiency $\left(\mathrm{n}_{\mathrm{ib}}\right)$ is calculated based on the beam radiation by neglecting the reflected radiation.

$$
\mathrm{n}_{\mathrm{ib}}=\frac{\mathrm{Q}_{\mathrm{u}}}{\left(\mathrm{I}_{\mathrm{b}} \mathrm{xr}_{\mathrm{b}}\right) \mathrm{WL}}
$$

\section{Experimental Results and Discussion}

Cylindrical parabolic collector is used to heat the water by automatic tracking. Using this parabolic trough 
collector, thermal performance of various reflectors is found out. Various experiments are performed to check the thermal performance of various reflectors on parabolic trough collector.[4] The concentrator has an aperture of a length of $1.8166 \mathrm{~m}$, while the absorber tube $(0.030 \mathrm{~m}$ inner and $0.032 \mathrm{~m}$ outer diameter $)$ has a concentric glass cover $(0.04 \mathrm{~m}$ inner and $0.043 \mathrm{~m}$ outer diameter) around it.Such a parabolic trough collector is used to check the thermal performance of various reflecting sheets. When the radiation falls on parabolic trough collector reflector then whole of the radiations will be collected on a line of absorber where the absorber is placed.

\section{A. Variation of Temperatures with Time for Aluminum} foil Sheet as Reflector

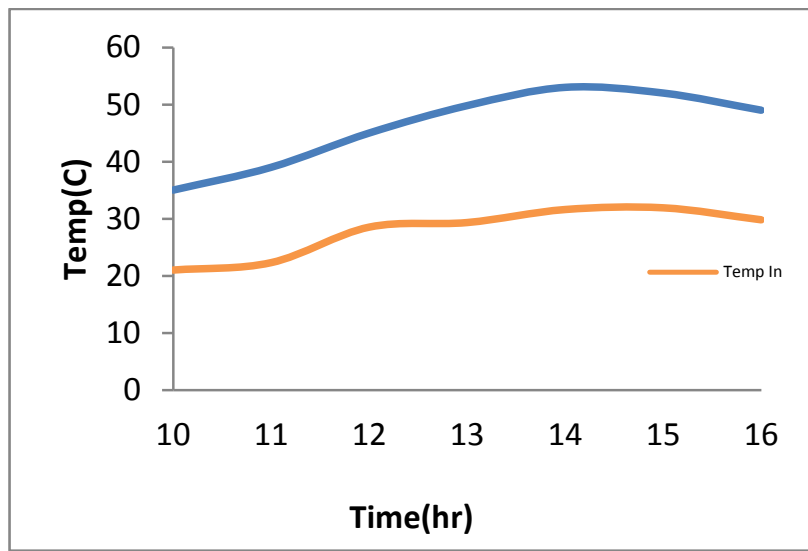

From the graph it is analyzed that the outlet temperature of water is minimum at 10:00 p.m. hours which increases gradually with time and reaches its maximum $53^{\circ}$ Cat $14: 00$ p.m.hour s. After that temperature starts to decreases gradually. This is because solar radiation falls perpendicularly on the trough and most of radiations are collected on given length of absorber.

B. Variation of Solar Temperature with Time for Mirror as Reflector

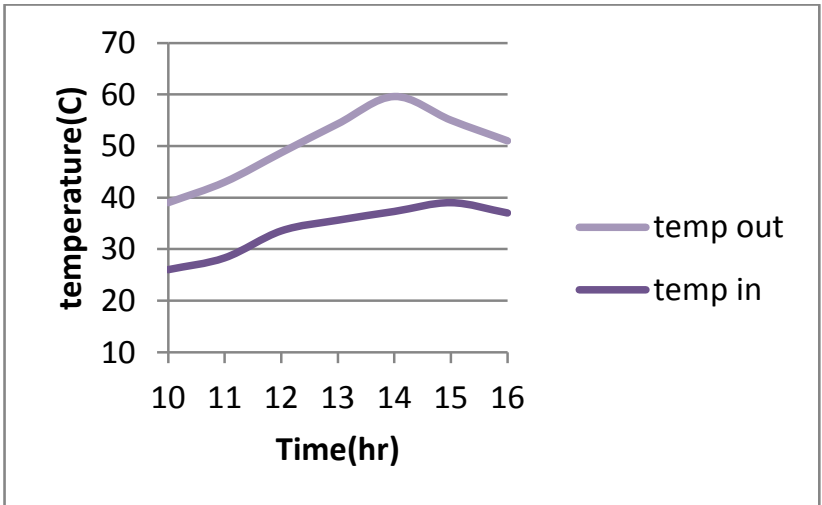

The maximum temperature is $59.6^{\circ} \mathrm{C}$, this is because solar radiation falls perpendicularly on the trough and most of radiations are collected on given length of absorber. Again the intensity of radiation remains almost constant from 12:30 p.m.hours to 14:00 p.m.hours and due to unsteady flow of heat temperature of pipe and temperature of water outgoing the pipe increase $4 \mathrm{~s}$. It is noted that outlet temperature with Aluminum sheet as reflector gives maximum temperature compare to steel and Aluminum foil.

C. Variation of Solar Intensity with Time for Aluminum foil Sheet as Reflector

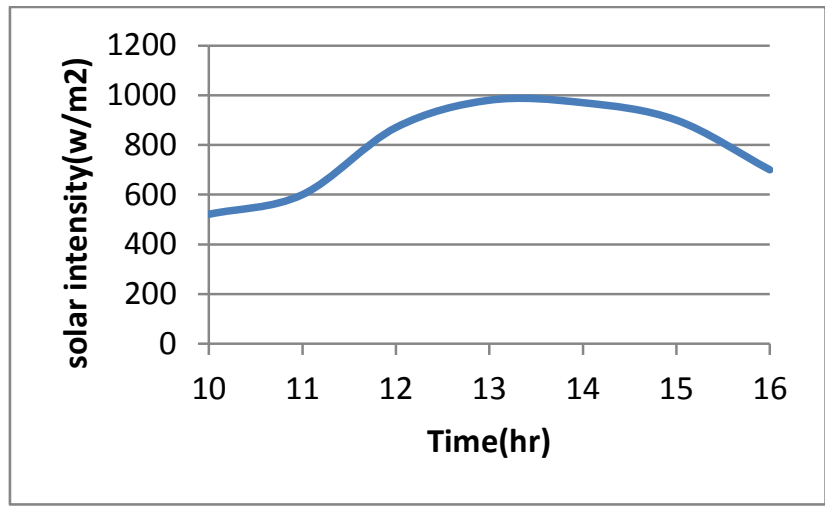

The collector was exposed to solar radiation for half an hour before the start of reading and experimental data was recorded after regular intervals of half an hour during the day time (0 9:00 P.M.to 17:00 P.M.)

From the graph it is analyzed that the outlet temperature of water is minimum at 10:00 P.M. which increases gradually with time and reaches its maximum $53^{\circ} \mathrm{C}$ at $14: 00$ P.M. After that temperature starts to decreases gradually. This is because solar radiation falls perpendicularly on the trough and most of radiations are collected on given length of absorber.

\section{Variation of Solar Intensity with Time for Mirror as Reflector}

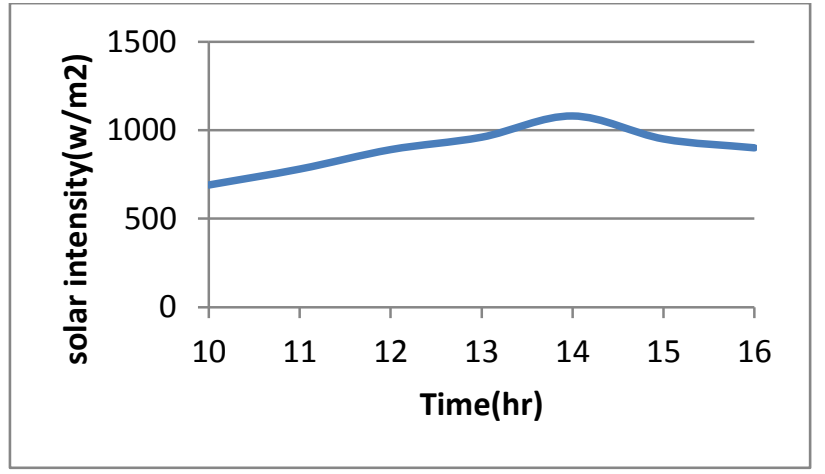

The initially efficiency decreases and then increases gradually. Efficiency decreases from 14:00p.m. hours to $16: 30$ hours except only at 15:30P.M. hours. This is because of dipping intensity, rate of which is faster than that of temperature drop. Hence the efficiency of collector increases. From 16:30P.M. hours to 17:00 hours efficiency increases rapidly. 


\section{Conclusions}

In this experiment, we have found out the thermal performance of various reflectors (Aluminum foil, Mirror) on a parabolic trough collector in one dimensional automatic tracking. We conclude the following results: We use Aluminum foil as reflector; the maximum temperature at the outlet of water is $53^{\circ} \mathrm{C}$ which can be used for water heating. This temperature is less compared to other reflectors. For Mirror maximum temperature is $48.2^{\circ} \mathrm{C}$, which is $14.5 \%$ more than Aluminum foil sheet as reflector at a water flow rate $0.1018 \mathrm{~kg} / \mathrm{s}$. Also efficiency, when using Aluminum foil as reflector compared to Mirror as reflector is $18.98 \%$.

\section{References}

Alok Kumar, Improvements in efficiency of solar parabolic trough IOSR Journal of Mechanical and Civil Engineering, 2013, 7, pp. 63-75.

Jain Neha,Comparative Study of Parabolic Trough Collector and Solar Power Tower Technology International Journal of Scientific Research and Reviews, 2012, 1(3), pp. 64-74.

Govindaraj Kumaresan, Rahulram Sridhar, RamalingomVelraj, Performance studies of a solar parabolic trough collector with a thermal energy storage system Energy, 2012, 47, pp. 395-402.

AvadheshYadav, Manoj Kumar, Balram, Experimental Study and Analysis of Parabolic trough Collector with Various Reflectors, International Journal of Mathematical, Computational, Physical and Quantum Engineering, 2013, 7(12), pp. 1157-1161.
K. Senthil, Manikandan, G. Kumaresan, R. Velraj and S. Iniyan, Parametric study of solar parabolic trough collector system, Asian journal of Applied Sciences, 2012, 5(6), pp. 384-393

AmirthamValanArasu and Samuel Thambu Sorna kumar Performance characteristics of the solar parabolic trough collector with hot water generation system, Thermal Science, 2006, 10(2), pp. 167-174.

M. Yaghoubi, F. Ahmadi, and M. Bandehee Analysis of Heat Losses of Absorber Tubes of Parabolicthrough Collector of Shiraz (Iran) Solar Power Plant, Journal of Clean Energy Technologies, Vol. 1, No. 1, January 2013, PP 34-39

Saad D. Odeh \& Hosni I. Abu-Mulaweh Design and development of an educational solar tracking parabolic trough collector system, Volume 15, Number 1, 2013, PP 21-2

Vandana Arora and Tanuja Sheorey Development and Performance Characteristics of a Low-Cost Parabolic Solar Collector, 2012 2nd International Conference on Power and Energy Systems (ICPES 2012), PP 80-8

MayurGhadge, Sachin Shinde Performance Analysis of a Parabolic Trough Collector with Modified Receiver2013 IJRSD.

A. Mohamad Heat losses from parabolic trough solar collectors, ter national journal of energy researchint. J. Energy Res. (2013), pp 401-405

WO 2012076949 A1, A solar parabolic trough collector or reflector system, Jun 14, 2012, [13] Suhas P sukhatme, J. K. Nayak, Solar Energy principles of thermal collection and storage, $3^{\text {rd }}$ ed., Tata mcgraw hill, New Delhi, 2012, pp. 79 88. 